\title{
NAS FRANJAS DO TEXTO E DO TEMPO: SENSIBILIDADES NO ESPAÇO DAS EXPERIÊNCIAS REDUCIONAIS
}

\author{
Eliane Cristina Deckmann Fleck
}

UNISINOS - São Leopoldo - RS

\section{Resumo}

Este artigo procura recuperar as sensibilidades como evidência do entrelaçamento entre experiência e expectativa e sua manifestação nas narrativas dos missionários jesuítas sobre a sua atuação junto aos Guarani da Província Jesuítica do Paraguai, no século XVII. As Cartas Ânuas analisadas apontam para a dimensão humana do missionário-narrador, apesar do rígido ordenamento da Ordem direcionado para a manutenção do tema da conversão como enredo e para o disciplinamento dos sentidos.

\section{Palavras-Chave}

Cartas Ânuas • Sensibilidade • Experiência

\section{Abstract}

This article seeks to reveal the sensibilities as evidence of the braiding of experience and expectations and their manifestations in the narratives of the Jesuit missionaries about their actuation among the Guarani of the Jesuit Province of Paraguay, in the $17^{\text {th }}$ century. The analyzed Cartas Ânuas reveal the human dimension of the missionary-narrator, despite of the strict prescriptions of the Jesuit Order directed for the maintenance of the subject of the conversion as plot and for the control of the senses.

\section{Keywords}

Cartas Ânuas • Sensibility • Experience 


\section{Sobre emoções e experiências}

O universo da comunicação humana não-verbal constitui um rico e apaixonante campo de investigação. Gestos, expressões faciais, movimentos e posturas corporais, tons de voz e silenciamentos comportam mensagens sobre estados emocionais reativos, em sua grande maioria. $\mathrm{O}$ estudo desses códigos e sinais tem na obra de Charles Darwin, A Expressão das Emoções no Homem e nos Animais, de 1872, a sua abordagem inaugural ao examinar a evolução das expressões emocionais humanas, a partir dos ancestrais animais. Outra importante contribuição foi dada pela Etologia e pela Psicologia experimental nas décadas de 50 e 60 do século XX.

Os sentimentos e as emoções, em geral, foram tratados de forma periférica, tanto nos trabalhos clássicos de Antropologia, como nos de História. Entre os trabalhos clássicos de Antropologia, talvez o mais elucidativo para uma reflexão acerca do lugar das emoções como objeto de estudo seja $A$ expressão obrigatória dos sentimentos, de Marcel Mauss, no qual o autor afirma que a expressão dos sentimentos apresenta uma dimensão de linguagem, na medida em que tem caráter ritualizado e sincronizado. Atualmente, a Antropologia e a Sociologia das emoções têm se proposto a investigar os fatores psicossociais que encontram expressão em sentimentos/emoções particulares e a evidenciar que fazem parte de um processo social; devem ser vistos dentro de contextos mais amplos e como aspectos importantes das interações entre os seres humanos e seu ambiente social e natural.

Defendendo que a "construção de um mundo inter-relacional se produz nos jogos de linguagem”, a antropóloga Paula Montero remete à noção wittgensteiniana de "acordo", ao propor que ele se produz no momento em que os grupos em interação desejam comunicar-se, e que, "embora pertençam a universos culturais distintos, estão dispostos a se comunicar", tendo consciência de que "só poderão se entender se compartilharem experiências comuns". ${ }^{1}$

$\mathrm{Se}$, em um primeiro momento, os estudos históricos pautaram-se pela relativização das categorias de emoções, mais recentemente - a partir da escrita da história das sensibilidades - verifica-se um movimento que as analisa como

\footnotetext{
${ }^{1}$ MONTERO, Paula. Introdução. Missionários, Índios e Mediação Cultural. In: MONTERO, Paula (org.). Deus na Aldeia. Missionários, índios e mediação cultural. São Paulo: Globo, 2006, p. 26.
} 
prática discursiva com efeitos externos, para além da sua condição de experiência interna, subjetiva, que extrapola o chamado domínio do privado.

Esta forma peculiar de fazer história, a partir da reconstrução sensível do tempo, determina "a necessidade de comprometer-se intelectual e sensivelmente com um tempo remoto para extrair-lhe os significados que reveste de forma quase confidencial"', encarando as dificuldades e possibilidades inerentes a essa abordagem precursora de interpretação das expressões e dos códigos sensíveis do passado.

Em entrevista concedida a Laurent Vidal e publicada pela Revista Brasileira de História, em 2005, Alain Corbin, inserindo-se nos debates recentes sobre a complexidade do emocional, da subjetividade e dos sentimentos, defende que o historiador das sensibilidades deve tomar como ponto de partida a maneira como as pessoas se representam, em distintos momentos da história, cabendolhe interpretar a coerência, as conexões dessas representações em seu universo. Para Corbin, cabe ao historiador "identificar a utilização dos sentidos que permitiu construir imagens do outro, dar forma ao imaginário social", "tentar entender a complexidade, essa simultaneidade de atitudes muito diferentes segundo os indivíduos e segundo os grupos" e "buscar colocar-se na pele dos atores, e reconstituir a lógica de cada um deles [...] para melhor entender, em seguida, o enfrentamento e os resultados"3.

Para o historiador uruguaio José Pedro Barran, a sensibilidade se constitui na faculdade de sentir, de perceber prazer e dor, que cada cultura tem e que se traduz nas impressões, nas imagens e nas representações, que tanto podem ser manifestas através do discurso, quanto das práticas sociais. As sensibilidades, segundo Barran, ao revelarem "los más escondidos presupuestos, el secreto de las conductas y, las razones del corazón” nos colocam em contato com "la medula de esa época, a los rasgos colectivos y seguramente intransferibles de una forma de sentir". ${ }^{4}$

Reconhecendo que a história das sensibilidades "diz respeito a zonas ainda pouco estudadas, que se estendem à margem da história das idéias, das repre-

${ }^{2}$ BARBIERO, Alan. Prefácio. In: ERTZOGUE, Marina H. e PARENTE, Themis G. (orgs.). História e Sensibilidade. Brasília: Paralelo 15, 2006, p. 13.

${ }^{3}$ VIDAL, Laurent. Alain Corbin: o prazer do historiador. Revista Brasileira de História. São Paulo : ANPUH/Humanitas, vol. 25, n.49, 2005, p. 11.

${ }^{4}$ BARRAN, José Pedro. História de la sensibilidad en el Uruguay. Tomo 1: La Cultura Bárbara: 1800 - 1860. Montevideo : Ediciones de la Banda Oriental, 1990, p. 12-13. 
sentações, dos corpos ou das imagens", Serge Gruzinski afirma que ela "toca o que se situa além da elaboração intelectual, mas nunca se separa dela" coincidindo "com os territórios do imaginário, mas tampouco se confunde com ele. [...] A história das sensibilidades interessa-se pelo indivíduo, por suas reações íntimas, por suas contradições abertas ou encobertas. [...] mas sempre para reinseri-los em conjuntos significativos [...] restituindo-lhes uma complexidade quase sempre escamoteada ou negada". 5

Segundo a historiadora brasileira Sandra Pesavento, "a sensibilidade revela a presença do eu como agente e matriz das sensações e sentimentos. Ela começa no indivíduo que, pela reação do sentir, expõe o seu íntimo. [...] Mas, mesmo sendo um processo individual, brotado de uma experiência única, a sensibilidade não é, a rigor, intransferível. Ela pode ser também compartilhada, uma vez que é, sempre, social e histórica" ${ }^{6}$ O conhecimento sensível opera, em razão disso, "como uma forma de reconhecimento e tradução da realidade que brota não do racional ou das construções mentais mais elaboradas, mas dos sentidos, que vêm do íntimo de cada indivíduo".?

A dimensão do mundo sensível não se rege por leis, regras ou razões, mas pelos sentimentos e emoções, que se traduzem externamente e se materializam em registros passíveis de serem resgatados pelo historiador. A apreensão dos seus significados se dá através da tradução destas subjetividades e destes sentimentos em materialidades, objetividades palpáveis que operam como a manifestação exterior de uma experiência íntima, individual ou coletiva. Estratégias de ação, palavras, valores, gestos e posturas corporais podem, em razão disso, ser nomeados como evidências do sensível, da experiência sensível de viver e de enfrentar o real e o não-real. ${ }^{8}$

\footnotetext{
${ }^{5}$ GRUZINSKI, Serge. Por uma história das sensibilidades. In: PESAVENTO, Sandra; LANGUE, Frédérique. Sensibilidades na História: memórias singulares e identidades sociais. Porto Alegre: Editora da UFRGS, 2007, p. 7-8.

${ }^{6}$ PESAVENTO, Sandra. Sensibilidades: escrita e leitura da alma. In: PESAVENTO, Sandra; LANGUE, Frédérique. op.cit., 2007, p. 13-14.

${ }^{7}$ PESAVENTO, Sandra J. Ressentimentos e Ufanismo: sensibilidades do Sul profundo. In: BRESCIANI, Stella e NAXARA, Márcia. Memória (res)sentimento. Indagações sobre uma questão sensível. Campinas : Ed. da UNICAMP, 2001, p. 225.

${ }^{8}$ Pesavento observa que "Naturalmente, a leitura dos sentimentos dá-se pelos caminhos da verossimilhança e não da pura veracidade, pois mesmo que os sentimentos e ressentimentos tenham deixado marcas objetivas de historicidade - toda interpretação responde ao caráter indireto e cifrado do que tais fontes podem revelar". (PESAVENTO, Sandra Jatahy. Na contramão da vida: razões e sensibilidades dos filhos malditos de Deus. In: ERTZOGUE, Marina e PARENTE, Themis. História e Sensibilidade. Brasília: Paralelo 15, 2006, p. 162).
} 
Deve-se, no entanto, considerar que essas sensibilidades, expressas através de sua capacidade mobilizadora, das reações que são capazes de provocar através da exteriorização ou ocultação dos sentimentos "que se insinuam em discursos, práticas e imagens", são vivenciadas "por personagens que são uma alteridade para nós. Um outro tempo, um outro no tempo, eis o mistério e o enigma a decifrar" ${ }^{\prime 10}$.

Animados por esse desafio, analisamos as narrativas dos missionários jesuítas sobre sua atuação junto aos Guarani ${ }^{11}$ da Província Jesuítica do Paraguai ${ }^{12}$ no século XVII, considerando a advertência feita por Juan Estenssoro, de que a conversão dos indígenas ao Cristianismo não deve ser percebida como "um processo linear de abandono progressivo de uma religião, substituída por outra", uma vez que "qualquer passo rumo à aceitação só é dado quando se oferece uma resposta eficaz às necessidades simbólicas equivalentes à do antigo rito, ou quando se cria a necessidade a que o novo rito responde" 13 .

Consideramos, ainda, a existência de uma "dinâmica indígena de absorção, rejeição e reelaboração da mensagem cristã" e de uma "dinâmica interna ao próprio discurso missionário, nas diferentes facetas em que ele se apresenta", que implicam, segundo Cristina Pompa, no acompanhamento, "na longa ou na breve duração, (d)a dinâmica do encontro-choque entre horizontes simbólicos diversos e (d)a construção de novos universos de significados 'nego-

\footnotetext{
${ }^{9}$ PESAVENTO, op. cit., 2001, p. 236.

${ }^{10}$ PESAVENTO, Sandra Jatahy. Palavras para crer. Imaginários de sentido que falam do passado. Nuevo Mundo Mundos Nuevos. [on line]. 2006, ${ }^{\circ} 6$. Disponível em http:// nuevomundo.revues.org/document1499.html. Acessado em 23/11/2006.

${ }^{11}$ A convenção da Associação Brasileira de Antropólogos, de 14 de novembro de 1953, estabelece que os nomes das tribos indígenas devam ser escritos com maiúsculas e ser usados no singular. Nas transcrições, respeitamos a grafia utilizada nos documentos consultados.

${ }^{12}$ A antiga Província do Paraguay abrangia, na época colonial, limites bastante mais extensos que os da moderna República Paraguaia. Recebendo o nome do rio que a banhava, compreendia uma imensa região que se estendia entre o Brasil e o Peru, até o Prata e o Oceano Atlântico. O antigo Paraguay limitava-se, ao norte, com a Capitania de São Vicente, pois a linha imaginária a separar os territórios de Portugal passava sobre o Iguape, no atual Estado de São Paulo; ao sul, com o Rio da Prata; a leste com o Oceano Atlântico e a oeste com a Província de Tucumán, atualmente território argentino. Os atuais Estados brasileiros do Paraná, Santa Catarina, Rio Grande do Sul e sul do Mato Grosso, subindo daí até a bacia do Amazonas, eram jurisdição do Paraguay. O Uruguai e a Argentina, com exceção de Tucumán, igualmente estavam sob sua jurisdição. No atual território boliviano, o Paraguay limitava-se com a Província de Santa Cruz de la Sierra.

${ }^{13}$ ESTENSSORO, Juan Carlos. O Símio de Deus. In: NOVAES, Adauto (coord.). A outra margem do Ocidente. São Paulo: Cia. das Letras, 1999, p. 188.
} 
ciados""14. Para a antropóloga brasileira, o projeto de catequese "exigiu a elaboração de uma linguagem de mediação, uma linguagem simbólica negociada, inteligível dos dois lados do encontro", empregada "para nomear o Outro, bem como para comunicar com ele" e que explicita o "trabalho de apreensão e de tradução da alteridade" ${ }^{15}$. Os relatos dos missionários refletiriam, nesta perspectiva, "um processo de 'tradução' em andamento" em que "o 'Outro' descrito pelas fontes já está, na maioria das vezes, há muito tempo, num processo de relacionamento com o 'Eu' ocidental, que é seu próprio 'Outro'”16.

\section{Sobre o tempo das cartas e o tempo das experiências : a conversão como enredo}

François Hartog, em seu O Espelho de Heródoto, de 1999, nos lembra que "o mundo que se conta encontra-se no mundo em que conta [...] na maneira como o texto faz crer, que não é tanto a quantidade de informação nova que se deve levar em conta, mas seu tratamento pelo narrador [..."117. As reflexões que se seguem são, em grande medida, tributárias dessa instigante afirmação, que nos animou a desvendar o mundo que se conta e o mundo em que conta manifesto nas Cartas Ânuas ${ }^{18}$ da Província Jesuítica do Paraguai referentes ao século XVII.

\footnotetext{
${ }^{14}$ POMPA, Cristina. Para uma Antropologia Histórica das Missões. In: MONTERO, Paula. (coord.) Deus na Aldeia. Missionários, índios e mediação cultural, São Paulo, Globo, 2006, p. 112.

${ }^{15}$ POMPA, op. cit., 2006, p. 123.

${ }^{16}$ POMPA, op. cit., 2006, p. 136.

${ }^{17}$ HARTOG, François. O Espelho de Heródoto. Ensaio sobre a representação do outro. Belo Horizonte: Ed. da UFMG, 1999, p. 372.

${ }^{18}$ Em relação às Cartas Ânuas deve-se observar que as "Litterae Anuae" consistem na correspondência periódica que os Padres Provinciais enviavam ao Padre Geral da Companhia de Jesus. Elas têm sua base nos relatórios anuais que o Provincial recebia dos superiores das Residências, Colégios, Universidades e Missões junto aos índios. Continham uma detalhada informação sobre as casas, suas obras, pessoas e atividades. Correspondem a um lapso de tempo de um ano ou de vários anos. Eram de responsabilidade dos superiores provinciais, que as assinavam e enviavam a Roma. De ordinário eram redigidas pelos secretários, ou por pessoas com capacidade para escrevê-las, designadas pelo Provincial. As Cartas Ânuas constituíam-se em relatórios administrativos para a Administração Geral da Ordem, mas não exclusivamente. Partilham também do gênero de cartas edificantes, pois selecionam fatos que possam ser úteis como propaganda para que mais jesuítas europeus viessem a trabalhar na América e para que conseguissem recursos financeiros para dar continuidade às obras que a Província tinha instalado. Visavam também a impressionar as autoridades civis e eclesiásticas com relação aos êxitos conseguidos. Com esse intuito elas foram traduzidas para o latim para que pudessem ser divulgadas nas Casas da Companhia de Jesus de toda a Europa. As Cartas Ânuas, relativas à Província Jesuítica do Paraguai, cobrem o período que vai de 1609 a 1675 e, após um intervalo de cerca de 40 anos, o período de 1714 a 1762.
} 
A antropóloga Paula Montero adverte que devemos ser capazes de colocar as categorias apresentadas nas fontes em seu contexto de produção, definindo o lugar dos atores, seus interesses e conflitos; e que devemos considerar o conjunto das fontes como uma narrativa na qual se depositam inúmeras vozes, em contraponto ou em uníssono, em diferentes tempos. Segundo ela, as fontes quando transcritas de uma forma suficientemente ampla devolvem, ao mesmo tempo, o contexto histórico em que se produziram determinados acontecimentos, o contexto narrativo em que se articulam as informações e o contexto cultural a partir do qual os relatos foram escritos e ao qual eram destinados ${ }^{19}$.

Michel De Certeau (1982), por sua vez, acentua a importância da subjetividade no processo do "fazer história", já que nele se inscreve a realidade do sujeito que escreve, que ocupa um lugar social e cultural no mundo, que é portador de um saber e do horizonte de expectativas de sua época. Já Cristina Pompa enfatiza que os "discursos que se constroem em meio a um processo de constante interpretação e tradução" de uma realidade em contínua mudança "são fluidos, negociados e históricos, dependendo também do interlocutor, para quem a informação é dirigida e que, possivelmente, a solicitou"20

Apesar de enfocar a escrita epistolar ou autobiográfica, Ângela de Castro Gomes, em A Escrita de Si, Escrita da História, nos coloca questões relevantes para a prática mais ampla de escrever Cartas : o tempo necessário - extraído da rotina diária - para que sejam redigidas; o domínio sobre o tempo narrado, em grande medida determinado pelos objetivos e pela sensibilidade do narrador; e, por fim, o lugar institucional ocupado por quem redige e que determina não só as razões, mas também os padrões discursivos - os códigos da escrita - que deverão ser observados ${ }^{21}$.

As Cartas Ânuas que analisamos apresentam-se como corpus documental orientado por prescrições institucionais ${ }^{22}$, o que não impede, contudo, que as reconstituamos a partir de três tempos de sua elaboração. Assim, temos um $1^{\circ}$

\footnotetext{
${ }^{19}$ MONTERO, Paula. Introdução. Missionários, Índios e Mediação Cultural. In: Deus na Aldeia. Missionários, Índios e Mediação Cultural. São Paulo: Globo, 2006, p. 13-14.

${ }^{20}$ POMPA, op. cit., 2006, p. 136.

${ }^{21}$ GOMES, Ângela de Castro. Escrita de Si, Escrita da História: a título de prólogo. In: Escrita de Si, Escrita da História. Rio de Janeiro: Editora FGV, 2004, p. 7-24.

${ }^{22}$ Ao serem contadas, as experiências são transpostas para o registro da narrativa, transformando-se em textos que são regulados por regras e convenções que regem esse domínio e que são próprias do ambiente sócio-histórico que as criou. No caso das Cartas Ânuas, as
} 
tempo, marcado pela interpretação imediata e utópica dos fatos que se traduz na realidade que se quer ver; um $2^{\circ}$ tempo, em que a realidade se impõe e questiona o afirmado, criando crises de paradigmas e, ainda, um $3^{\circ}$ tempo, que se caracteriza pelo processo de reelaboração para a afirmação de um novo paradigma que, simultaneamente, dê espaço à visão utópica e absorva a desordem criada a partir da ruptura imposta pela realidade.

Como bem nos mostra Marshall Sahlins, os significados, ao serem atualizados, são colocados em risco na ação, tanto pela conjuntura histórico-cultural presente, quanto pelo valor intencional subjetivo de seu uso pelos sujeitos ativos, o que evidencia a tensão produtiva das dinâmicas de inovação e recriação na ação simbólica $^{23}$. Para Paul Ricoeur, o que está em jogo nesta trama da existência narrada é a tensão permanente entre as forças organizadoras da ordem e da concordância e as forças da discordância, do caos, da surpresa, do inesperado e arbitrário do destino ${ }^{24}$. Este mesmo autor propõe que através da categoria de "identidade narrativa" se alcance uma interessante compreensão das relações entre indivíduo, sociedade e historicidade, que nos permite reconhecer que a fronteira existente entre estes campos não deve ser entendida como indicador de oposição e diferença, mas como uma área de negociação e de trânsito entre esfe$\operatorname{ras}^{25}$, que desvela o quão estratégica é a tarefa do contar, do narrar.

Considerando o objetivo de desvendá-las nesta perspectiva, recorremos às reflexões propostas por Reinhardt Koselleck sobre os conceitos de "experiên-

prescrições que orientam o registro das experiências vividas pelos missionários foram sistematizadas pelo fundador da Companhia de Jesus, Santo Inácio de Loyola, no século XVI. Cabe ressaltar que a Companhia de Jesus, inserida no ambiente humanista e renascentista, construiu seu conhecimento retoricamente, além de atribuir significativa importância à disciplina de retórica no seu sistema pedagógico. De acordo com Fernando Torres Londoño, o registro dos avanços e das dificuldades encontradas pelos missionários jesuítas era uma exigência da Companhia de Jesus, enquanto ordem de letrados que nasceu e se espalhou pelos quatro continentes sob o domínio da escrita, constituindo-se em "base de um sistema de informações que envolvia toda uma estrutura de registros [...] em função de assegurar a comunicação e fornecer ao Superior Geral e outros superiores os elementos para suas decisões naquele delicado equilíbrio entre o centralismo e a autonomia [...]". (LONDOÑO, Fernando Torres. Escrevendo Cartas. Jesuítas, escrita e missão no século XVI. Revista Brasileira de História. São Paulo, ANPUH/Humanitas, v. 22, nº 43, 2002, p. 21).

${ }^{23}$ SAHLINS, Marshall. Ilhas de História. Rio de Janeiro: Jorge Zahar Editor, 1990, p. 189.

${ }^{24}$ RICOEUR, Paul. Tempo e narrativa. Tomo I. Campinas/SP: Papirus, 1994, pp. 76-77.

${ }^{25}$ RICOEUR, Paul. Tempo e narrativa. Tomo III. Campinas/SP: Papirus, 1997, p. 429. 
cia" e de "expectativa", que, segundo ele, se constituem em categorias adequadas para se obter um indicador da temporalidade exatamente por entrecruzarem o passado e o futuro ${ }^{26}$. Para este autor, a experiência, por encontrar-se saturada de realidade, elabora os acontecimentos passados vinculando-os às possibilidades cumpridas ou fracassadas. É, em razão disso, que ela consiste na referência única para as expectativas. Já o futuro, se constitui em "horizonte", em um espaço de experiência apenas projetado.

É exatamente esta relação complexa entre experiência e expectativa que suscita as diferentes soluções discursivas, pois mesmo que os acontecimentos passados tenham sucedido de maneira definitiva, as experiências baseadas sobre eles podem se modificar com o passar do tempo. ${ }^{27}$ As experiências se superpõem, impregnando-se umas das outras, exatamente porque as novas esperanças ou as frustrações abrem brechas e repercutem sobre elas. A estrutura temporal da expectativa pressupõe necessariamente a experiência. Quando, entretanto, sucede aquilo que não se esperava, isto é, quando se estabelece uma ruptura do horizonte de expectativa, apresenta-se, então, uma nova experiência. Estas considerações sobre o tempo histórico nos permitem resgatar outra reflexão proposta por François Hartog, a de que "as histórias devem ser lidas uma em relação com a outra, mesmo que a cronologia as separe" ${ }^{28}$.

Desta forma, o espaço de experiência e o horizonte de expectativa entrelaçam, cada um, o passado e o futuro de maneira desigual, determinando uma concepção de tempo histórico não-linear e evolutivo, já que sua referência é o ritmo das experiências vividas e das expectativas dos indivíduos que agem e sofrem.

A evocação negativa do passado - simultaneamente tomado como presente, como a realidade na qual estavam atuando os missionários - foi um dos instrumentos mais utilizados para a evocação positiva de um futuro, no qual reinariam a civilização e os princípios cristãos. É a partir dessa perspectiva de análise do tempo das cartas e do tempo das experiências - e que considera

\footnotetext{
${ }^{26}$ KOSELLECK, Reinhardt. Futuro pasado. Para una semántica de los tiempos históricos. Barcelona: Ediciones Paidós, 1993.

${ }^{27}$ Esta profunda ligação entre narrativa e experiência é reiterada por Walter Benjamin como uma "qualidade comunicativa em crise", na medida em que revela o valor da experiência como fonte e possibilidade da narrativa. (BENJAMIN, Walter. Obras escolhidas: magia e técnica, arte e política. V. 1. São Paulo: Brasiliense, 1987, p. 198).

${ }^{28}$ HARTOG, op. cit., 1999, p. 372.
} 
tanto a sobreposição dos horizontes de expectativas e dos horizontes de temores, quanto a evocação negativa do passado e a evocação positiva do futuro que se devem resgatar as orientações relativas à atividade epistolar, bem como as primeiras instruções dadas aos jesuítas destinados ao trabalho missionário na Província Jesuítica do Paraguai.

Fernando Torres Londoño lembra-nos que a Companhia de Jesus surgiu e estendeu sua atuação sobre os quatro continentes no século XVI, "sob o domínio da escrita", que "cumpriu um papel estratégico na construção da missão"29. A atividade epistolar foi concebida como uma resposta ao desafio da dispersão e da necessidade de estabelecer canais e formas de comunicação, bem como um meio de cuidar da circulação de informações. As próprias Constituições da Companhia de Jesus estabeleceram "responsabilidades para a geração das informações e destinatários destas", fixaram prazos, determinaram a produção de cópias e definiram sua circulação, “consideradas as línguas e apontados os temas a serem tratados nas cartas" ${ }^{30}$.

A decisão do Superior Geral da Companhia de Jesus de reunir, em 1601, as regiões do Rio da Prata, Tucumã e Chile, numa Província independente e denominada Paraguay, determinou a realização do $1^{\circ}$ Concílio do Rio da Prata, em Assunção, no ano de 1603. As determinações resultantes desse Concílio tornaram-se um referencial para o trabalho missionário, refletindo-se nas duas Instruções formuladas pelo $\mathrm{P}^{\mathrm{e}}$. Diego de Torres Bollo, em 1609 e 1610.

Essas Instruções estabeleceram as metas a serem alcançadas pelos missionários e os meios a serem empregados, tanto para o ensino da doutrina aos índios, quanto para a reforma dos costumes dos espanhóis ${ }^{31}$, enfatizando a neces-

${ }^{29}$ LONDOÑO, op. cit., 2002, p. 13.

${ }^{30}$ LONDOÑO, op. cit., 2002, p. 15. A oitava Parte das Constituições trata dos "meios de unir com a cabeça e entre si aqueles que estão dispersos" e refere à importância da correspondência entre súditos e superiores, com "o intercâmbio freqüente de informações entre uns e outros, e o conhecimento das notícias e comunicações vindas de diversas partes" para a "união dos espíritos" e para o governo da Companhia. (LOYOLA, Inácio de. Constituições da Companhia de Jesus e normas complementares. São Paulo: Edições Loyola, 2004, p. 85). Segundo Londoño, "aparece aqui a consciência clara de que nas cartas se produza a imagem da Companhia para provocar edificação e apoio", pois "a gestação da escrita" era "encarada como uma montagem definida pelos seus fins e destinatários" (LONDOÑO, op. cit., 2002, p. 19).

${ }^{31}$ MATEOS, F. El Primer Concilio del Río de la Plata en Asunción (1603). Misionalia Hispánica, n. 78, set./dez. 1969, p. 321. 
sidade de "tirar-lhes os pecados públicos e pô-los sob policiamento" 32 , bem como de afastá-los dos "perniciosos feiticeiros" que incitavam os índios a permanecerem em suas superstições.

Os membros da Companhia de Jesus tinham sua atuação como missionários também orientada pelas Constituições, nas quais Inácio de Loyola, partidário da concepção tomista de que o conhecimento penetrava no intelecto pela via dos sentidos, ${ }^{33}$ recomendava um cuidado especial para com eles. Este "disciplinamento dos sentidos" é expresso desta forma nas Constituições : "Todos tengan especial cuidado em guardar com mucha diligencia los ojos y oídos y la lengua, de todo desorden"

Nos registros da atuação desses missionários na Província Jesuítica do Paraguai - orientados por prescrições constantes nos documentos fundantes da Companhia de Jesus - mereceram especial destaque os casos edificantes ou sucessos notáveis por apontarem para a conversão e para a almejada mudança de conduta dos indígenas. ${ }^{35}$ Vale lembrar aqui as reflexões de Walter Benja-

${ }^{32}$ Apud RABUSKE, Arthur S.J. A Carta Magna das Reduções Jesuíticas Guaranis. Estudos Leopoldenses, v. 14, n. 47, 1978, p. 25.

${ }^{33}$ Para Loyola, os sentidos deveriam obedecer à razão. A mortificação das paixões e o controle dos sentidos tinham a função explícita de robustecer o espírito, impedindo que dificultassem a salvação da alma e o apostolado. O intelecto, em um ato de vontade, deveria subjugá-los, ordenando os afetos e restringindo os prazeres considerados inferiores. Evidencia-se aqui que além das prescrições para a atividade epistolar, as Constituições estabeleceram também rígidas orientações sobre a expressão de sentimentos pelos missionários, as quais, inevitavelmente, se refletiriam em seus registros.

${ }^{34}$ Apud IPARRAGUIRRE, Ignácio. Obras Completas de Ignacio de Loyola. Madrid : Biblioteca de Autores Cristianos, 1952, p. 427-428.

${ }^{35}$ Considerando as orientações fixadas por Inácio de Loyola e, posteriormente, pelo $\mathrm{P}^{\mathrm{e}}$. Polanco, foi estabelecido o que deveria ser comunicado nas cartas e como isto deveria ser feito. Determinou-se, então, quais informações poderiam atingir um público externo e quais seriam de uso interno e exclusivo da Companhia. Assim, a carta passou a ser composta de duas partes : a carta principal, ou edificante, e a que circulava em âmbito estritamente institucional, ou hijuela., na qual caberia "tudo o que pudesse não edificar, o emocional, o primário, o espontâneo ou sem elaboração e por isso não deveria ser mostrado ou dado a público" (LONDOÑO, op . cit., 2002, p. 19). A produção de "uma imagem da Companhia através das letras" é também ressaltada por Londoño que alerta que "sendo este o objetivo, a missiva não poderia ser deixada ao acaso das impertinências cotidianas dos padres ou à intensidade de seus sentimentos espirituais", devendo os padres "ter a consciência de que estavam produzindo um texto para ser interpretado e lembrado" (LONDOÑO, op. cit., 2002, p. 18). 
min acerca do narrador que suprime alguns aspectos e faz realçar outros, tendo como critério a harmonização do enredo da narrativa com o conjunto de acontecimentos mais amplos. Hartog, por sua vez, nos adverte de que "o narrador diz, mas o faz dizendo de certo modo, dizendo o que é notável"36.

Trata-se, portanto, de considerar as implicações da ênfase dada aos registros edificantes e da omissão de outros, como observado na Carta Ânua de 16371639 , em que o $\mathrm{P}^{\mathrm{e}}$. Zurbano as justifica por não atenderem à fórmula prescrita pelo padre Geral da Companhia e que previa o registro somente do realizado para "glória de Deus e para a salvação das almas" levaria à predominância quase absoluta desses registros, reiterados de forma retórica e monótona, o que foi atestado - pelo mesmo padre - na Ânua correspondente ao período de 1641-1643, na qual informa que "haviam ocorrido casos de edificação que por serem comuns, não os registrava" ${ }^{38}$.

Observando a fórmula prescrita pela própria Companhia de Jesus, as Ânuas apresentam diferentes razões para o enaltecimento dos feitos dos missionários, que vão desde a necessidade de afirmação do apostolado da Companhia de Jesus, até a preocupação com a proteção política e o amparo financeiro do Estado Espanhol, o despertar de novas vocações e, ainda, as campanhas de difamação perpetradas pelos inimigos da Companhia na Europa. Segundo Paul Ricoeur, para compreender as relações entre o mundo do texto e o do leitor é necessário considerar a existência de três momentos distintos : "(1) a estratégia fomentada pelo autor e dirigida para o leitor; (2) a inscrição dessa estratégia na configuração literária; (3) a resposta do leitor, considerado quer como sujeito que lê, quer como público receptor" 39 . Já Hartog, ao ressaltar que "um texto não é uma coisa inerte, mas inscreve-se entre um narrador e um destinatário", aponta para as relações entre o texto e o "saber compartilhado" de uma época, "um conjunto de saberes semântico, enciclopédico e simbólico que lhes é comum”, que torna possível a comunicação ${ }^{40}$.

\footnotetext{
${ }^{36}$ HARTOG, op. cit., 1999, p. 372.

${ }^{37}$ In: MAEDER, Ernesto J. A. (org.). Cartas Ânuas de la Provincia del Paraguay, 1637 1639. Buenos Aires: FECIC, 1984, p. 107.

${ }^{38}$ DOCUMENTOS DE GEOHISTÓRIA REGIONAL (D. G. R.) - Cartas Ânuas de la Provincia Jesuítica del Paraguay (1641 - 1643). Resistencia, Chaco : Instituto de Investigaciones Geohistóricas, 1996, p. 119.

${ }^{39}$ RICOEUR, op. cit., 1997, p. 277.

${ }^{40}$ HARTOG, op. cit., 1999 , p. 39 e 49.
} 
Essas razões definiram, de certa forma, a apresentação dos relatos dos missionários ao padre Provincial e deste ao padre Geral da Companhia de Jesus, radicado em Roma, nos quais constatamos a existência de padrões discursivos que apontam para a identificação de três momentos condicionados ao contexto político americano e até europeu. Os registros que caracterizam as duas primeiras décadas são marcados pela insistente negação e diabolização da cultura guarani. Neles são enfatizadas as ações nocivas dos feiticeiros; os movimentos de resistência xamanística; as dificuldades encontradas pelos missionários, tanto em relação à garantia da sua própria sobrevivência, quanto em relação à continuidade e ao êxito do trabalho missionário. A experiência determina que o presente-passado seja alvo de evocações negativas, reforçando e conformando as evocações positivas do futuro. ${ }^{41}$

As pestes e os períodos de fome, ainda que referidos no período anterior e posterior, ocupam de forma significativa os relatos do período compreendido entre as décadas de 30 e 50, na medida em que passaram a ser as razões potenciais do fracasso da ação missionária entre os Guarani. Aqui a experiência se impõe de tal forma, a ponto de implicar a mencionada crise de paradigmas tanto em relação ao presente, quanto em relação ao futuro. O horizonte de temores se sobrepõe ao horizonte de esperanças, determinando uma concomitância de estados de euforia e de pessimismo em relação aos resultados alcançados ou por alcançar.

\footnotetext{
${ }^{41}$ Deve-se, ainda, considerar que o termo "experiência" tinha um sentido específico para os membros da Companhia de Jesus, o que, com certeza, orientou sua atuação e influenciou a narrativa de sua atuação. De acordo com Pacheco, "tal como é empregado entre os jesuítas, o termo experiência deve ser entendido a partir de um complexo feixe de influências, além da assumida posição filosófica aristotélico-tomista, é preciso dizer que parece existir também uma influência agostiniana. E, para além do aspecto puramente filosófico, quando se fala de experiência na Companhia de Jesus, se está tratando com uma categoria que também pertence ao universo da regulação tanto espiritual e corporal quanto jurídica e institucional. [...] podese concluir que experiência é o contraponto de uma mística do abstrato [...] é preciso a experiência imediata, é preciso o conhecimento direto proporcionado pelos sentidos e pela consciência de si mesmo, é preciso a experiência das coisas percebidas, que são conhecidas na medida em que as vivemos, as tocamos, ouvimos, experimentamos. [...] Enfim, aprende-se a ser jesuíta "experimentando" o que seja ser um jesuíta [...] É a vida de Inácio: uma experiência-modelo que se torna a prescrição explícita de um modelo de imitação. [...] Vê-se que a experiência está intimamente ligada a um conhecimento de si mesmo e de Deus, bem como de virtudes morais [...]" (PACHECO, Paulo Roberto de Andrada. Experiência como fator de conhecimento na psicologia-filosófica aristotélico-tomista da Companhia de Jesus (séculos XVIXVII). Memorandum, n. 7, 2004, p. 58-87. Disponível em : http ://www.fafich.ufmg.br/ $\sim$ memorandum/artigos07/pacheco01.htm).
} 
A marca inconteste da experiência sobre os missionários não impede, contudo, que a documentação das décadas de 60 e 70 mantenha a ênfase nos relatos edificantes. Os missionários-narradores, no entanto, o fazem com a intenção de ressaltar o estado de perfeição atingido pelas reduções, com a finalidade de obter reforços através do envio de jovens missionários e, principalmente, de desfazer intrigas contra a Companhia de Jesus, decorrentes de sua opção pela proteção aos indígenas. A retomada das expectativas no futuro parece sinalizar para a superação do passado, contudo, o que se observa é que os missionários se vêem forçados - e de forma contundente - a registrar o retorno insidioso do passado no presente.

Optando por um corte diacrônico da documentação, constata-se que as Cartas dos anos de 1610-1613, período que se refere à implantação do modelo reducional, por exemplo, enfatizam as demonstrações de temor dos indígenas de morrerem infiéis e de irem para o inferno em razão disso ${ }^{42}$. Os missionários não descuidam de valorizar que a assimilação - pelos indígenas - de que castigos se abatiam sobre os infiéis e pecadores, os levava a procederem de acordo com suas recomendações, rompendo com suas pautas tradicionais; isto é, com o passado evocado negativamente pelos missionários ${ }^{43}$. Considerandose que a experiência dos missionários - dado o seu caráter inaugural - é ainda marcada pela projeção no futuro, nos horizontes de expectativa, são, no mínimo, surpreendentes as referências à conversão instantânea mediante a administração do sacramento do batismo a velhos e a moribundos e sua vinculação com a garantia da salvação ${ }^{44}$.

As referências à conversão bem sucedida - expressa na urgência com que os indígenas buscavam a confissão - ficam evidentes como elemento estruturador do enredo das Ânuas, podendo ser também encontradas na Carta Ânua de 1637 - 39. Neste registro constata-se - decorridos já 30 anos - a marca da

${ }^{42}$ In: PASTELLS, R. P. Pablo. Historia de la Compañía de Jesús en la Provincia del Paraguay. Tomo I. Madrid : Librería General de Victoriano Suárez, 1912.

${ }^{43}$ In: MAEDER, Ernesto J. A. Cartas Ânuas de la Provincia del Paraguay, 1632 - 1634. Buenos Aires : Academia Nacional de la Historia, 1990, p. 91.

${ }^{44}$ DOCUMENTOS PARA LA HISTORIA ARGENTINA (D. H. A.). Tomos XIX, XX, Iglesia. CARTAS ÂNUAS. Cartas Ânuas de la Provincia del Paraguay, Chile y Tucumán, de la Provincia de la Compañia de Jesús. Vol. 2 - 1615-1637. Buenos Aires : Talleres S.A. Casa Jacobo Peuser, 1929, p. 77 e 289. 
experiência interferindo na narrativa, na medida em que o missionário observa que os indígenas nem sempre tinham o que confessar e que o faziam "para ganhar mais graças sacramentais" 45 . Mais adiante, na mesma Carta, o relator Pe. Francisco Lupercio de Zurbano informa que os Guarani, apesar de serem muito apegados à confissão, são também muito inclinados a fazer más confissões. O que mais nos chama a atenção é que o passado-presente se impõe de tal forma que o missionário não deixa de explicitar seu horizonte de temores, comprometendo sua esperança no futuro, ao afirmar que "tal comportamento se compreendia devido à rudeza e à incapacidade dos indígenas de se aprofundarem nos conhecimentos religiosos" ${ }^{\prime 4}$.

Aqui se constata a sobreposição que queremos explorar; a do tempo da narração das Cartas - que obedece às prescrições - e a do tempo da experiência-que confunde e confronta, interferindo no registro. Esta sobreposição se explicita numa operação discursiva que não pode deixar de contemplar o que deve ser narrado ${ }^{47}$ - observando criteriosamente o que deve ser omitido - mas que acaba revelando o próprio narrador.

Decorridos dez anos, o $\mathrm{P}^{\mathrm{e}}$. Juan Ferrufino deixa entrever em suas observações, na Ânua de 1647-49, que a tarefa da conversão não estava concluída e que as adversidades continuavam tendo uma função "educativa", devendo-se, por isso, perseverar nas mesmas estratégias de conversão ${ }^{48}$. A necessidade de constantemente fazê-los sentir remorsos, além de indicar a freqüência com que ocorriam desvios de conduta ou transgressões, atestam para a concomitância de tempos, passado-presente, e apontam para um horizonte de esperanças construído sobre a superação dos temores e da idéia de um futuro promissor.

\footnotetext{
${ }^{45}$ In: MAEDER, Ernesto J. A. (org.). Cartas Ânuas de la Provincia del Paraguay, 1637 1639. Buenos Aires : FECIC, 1984, p. 96.

${ }^{46}$ In: MAEDER, op. cit., 1984, p. 34.

${ }^{47}$ Para Londoño, "ao escrever sobre a missão, os jesuítas o faziam utilizando um registro ou tom inspirado na subjetividade de sua vivência do carisma inaciano" (LONDOÑO, op. cit., 2002, p. 13). Valendo-nos das reflexões feitas por P. A. Fabre (2000), a experiência jesuítica pode ser definida como uma série de atividades que garantem a identificação do indivíduo com a instituição e a reprodução/manutenção dessa mesma instituição, determinando a filiação a um modus operandi e a uma maneira habitual da instituição de refletir, meditar e agir, que lhe permite viver firmemente nas "cosas de Instituto".

${ }^{48}$ CARTAS ÂNUAS. Cartas Ânuas de la Provincia Jesuítica del Paraguay (Año 1668). Traducción de Carlos Leonhardt, S.J. Buenos Aires, 1928. (Mimeo), p. 155.
} 
O passado condenado, evocado negativamente, se manifesta tão vivamente no presente a ponto de as transgressões continuarem a se constituir em preocupação recorrente dos missionários, como pode ser observado na Ânua de $1668^{49}$, ano que se insere na etapa tradicionalmente associada à consolidação das reduções jesuítico-guaranis, como já referido. Nesta mesma Carta, apesar de informar sobre a frequiência com que ocorriam as confissões, o missionário confere importância e registra as experiências subjetivas dos indígenas, sugerindo que a vergonha e a humilhação que sentiam - ao se confessarem com vários confessores - os levassem a abandonar as condutas indesejáveis, evitando a repetição da situação de constrangimento ${ }^{50}$. Deve-se ter em conta, no entanto, que o tempo das Cartas reteve e consagrou a percepção de que os indígenas buscavam o batismo e a confissão atraídos pela promessa da absolvição dos pecados e da garantia das bênçãos divinas.

Os registros feitos pelos missionários parecem indicar, realmente, uma alteração significativa nas atitudes dos indígenas. A moderação das emoções, a normatização de ações e a eliminação de comportamentos inconvenientes aparecem vinculadas à prática do jejum, à penitência e à autoflagelação, assumindo a função de elemento estruturador para o enredo das Ânuas. Apesar de, por vezes, as considerarem exageradas, os missionários não escondiam sua satisfação, na medida em que as interpretavam como indício da conversão dos indígenas, levando-os a ratificar a evocação negativa do passado e a evocação positiva do futuro ${ }^{51}$.

$\mathrm{O}$ espaço da experiência confrontado com o horizonte de expectativas fica bastante evidente também em registros que referem as causas e os efeitos das epidemias, nos quais os missionários admitem que as doenças se deviam às condições de assentamento, à transmigração e às mudanças climáticas e reconhecem os experimentalismos nas terapêuticas curativas com "remédios do campo daquela região" 52 . O tempo das Cartas, contudo, se sobrepõe ao tempo da experiência, mantendo a percepção negativa sobre as práticas curativas indígenas ao informar que os feiticeiros eram vigiados por manterem suas antigas superstições e terapêuticas.

O senso de observação prática dos missionários e a relação que estabeleceram entre as doenças e as condições de assentamento das populações indígenas

\footnotetext{
${ }^{49}$ CARTAS ÂNUAS, op. cit., 1928, p. 20.

${ }^{50}$ CARTAS ÂNUAS, op. cit., 1928, p. 20-21.

${ }^{51}$ In: MAEDER, op. cit., 1984, p. 129.

${ }^{52}$ In: MAEDER, op. cit., 1984, p. 88.
} 
podem ser constatados nos registros que as vinculam às terras úmidas, pantanosas e cheias de mosquitos e víboras, na verificação de que a escassez do sólido alimento produzia toda a sorte de enfermidades e nos registros bastante detalhados sobre o processo das doenças (o contágio, as tentativas de cura - empíricas ou exorcistas - ou então a morte), bem como das principais enfermidades (gripe, disenteria, lepra, sarampo, tifo, varíola) que se abatiam sobre os indígenas reduzidos e os colonos espanhóis instalados nos pueblos.

Este embate entre racionalismo e misticismo fica também evidenciado na Ânua de $1637-39^{53}$, em que o $P^{\mathrm{e}}$. Zurbano, ao relatar a punição de indígenas que roubam e carneiam um boi, a atribui, primeiramente, à justiça divina e, logo após, ao consumo em demasia de carne - sem descuidar, no entanto, de ressaltar os desdobramentos do ocorrido, em termos de conduta dos indígenas.

Uma situação similar nos é apresentada, em 1663, pelo P $P^{\mathrm{e}}$. Andrés de Rada, no relato que faz sobre as imagens que vertiam lágrimas e para o que apresenta duas interpretações, a da decomposição dos ingredientes usados na pintura, situação muito comum em quadros a óleo, e a da intervenção milagrosa da divina Providência ${ }^{54}$. À semelhança de Zurbano, Rada sugere que, em termos de explicação, prevaleça sempre aquela que promove reforma de costumes, já que produz efeito moral.

Por outro lado, as marcas das experiências dos missionários nos padrões discursivos não parecem ter se limitado, exclusivamente, à ratificação da evocação negativa do passado e da evocação positiva do futuro. Em razão disso, as recorrentes informações sobre igrejas adornadas, altares erguidos e decorados, caminhos limpos, demonstrações de alegria e bailes conforme seu costume, não parecem - apesar de vinculados ao passado condenado -, comprometer, no entendimento dos missionários, a devoção e a piedade expressas nas missas, procissões, festas religiosas e penitências ${ }^{55}$. Afinal, "ali onde antes havia apenas feras, eram encontrados anjos em forma humana" a verdadeira fé, e se encontravam domesticados e reduzidos" $" 57$.

\footnotetext{
${ }^{53}$ In: MAEDER, op. cit., 1984.

${ }^{54}$ CARTAS ÂNUAS. Cartas Ânuas de la Provincia del Paraguay referente a los años 1663 1666. Traducción de Carlos Leonhardt, S.J. Buenos Aires, 1927. (Mimeo), p. 103.

${ }^{55}$ In: MAEDER, op. cit., 1984, p. 93-94.

${ }^{56}$ CARTAS ÂNUAS, op. cit., 1927, p. 107.

${ }^{57}$ D. G. R., op. cit., 1996, p. 79.
} 
Também na Ânua de 1672-1675, a experiência parece se impor no tempo das Cartas, como evidenciado no registro de que "baixaram de ali os pobres índios em massa, com manifestações de grande alegria, celebrando a chegada dos missionários com bailes e música à sua maneira" ${ }^{58}$. Situações semelhantes a esta podem ser encontradas na Ânua de 1641-1643, como a que refere que:

Os domingos e as festas são celebradas com toda a solenidade, com missa cantada e sermão; as igrejas estão muito bem adornadas com o adorno possível e quando levam o Santíssimo aos doentes, varrem e adornam as ruas com ramos e flores, levando velas de cera silvestre e se fazendo acompanhar de música de chirimías. ${ }^{59}$

Segundo Hartog, "a alteridade que é assim reduzida, canalizada e conjurada pode, todavia, operar no texto no e pelo jogo da polissemia, como no sentido dado à expressão 'à sua maneira" "60. No caso das Ânuas, ainda que esta alteridade permaneça abominável e condenável para o missionário, passa a fazer sentido para ele, dando início àquilo que denominamos de exegese, de interpretação da experiência.

Neste sentido, as experiências vividas pelos missionários jesuítas nas reduções da Província Jesuítica do Paraguai e registradas nas Cartas Ânuas foram alvo - simultaneamente - da evocação do passado e do futuro, do horizonte de esperanças e do horizonte de temores, definindo - em grande medida - o tratamento dados pelos missionários-narradores ao tema da conversão, ora exitoso, ora comprometido pelo retorno insistente do passado no presente.

A observância da fórmula prescrita para a redação das Ânuas determina numa análise diacrônica - a percepção de uma progressão linear, de uma normalização do processo de conversão dos Guarani, na medida em que os três tempos das Cartas apontam para o estado de perfeição atingido pelas reduções. Uma análise sincrônica, contudo, nos revela a existência concomitante de tempos marcados pelas experiências, que alternam o passado e o futuro, a esperança

\footnotetext{
${ }^{58}$ CARTAS ÂNUAS, op. cit., 1927, p. 25-26.

${ }^{59}$ D. G. R., op. cit., 1996, p. 77.

${ }^{60}$ HARTOG, op. cit., 1999, p. 133-135.
} 
e o temor, e que, embora apontem para a manutenção do tema da conversão como enredo, reforçam a dimensão humana do relator-narrador.

Uma dimensão que se expressa naquilo que tão sugestivamente Michel de Certeau denominou de franjas do discurso, que perturba o "consagrado sistema de interpretação" do as visões de mundo e a cultura sensível dos indivíduos e de uma época.

${ }^{61}$ DE CERTEAU, Michel. A Escrita da História. Rio de Janeiro : Forense Universitária, 1982, p.1 16.

${ }^{62}$ DE CERTEAU, op. cit., 1982, p. 227. 